\title{
Selective recovery of the cultivation-prone components from mixed trypanosomatid infections: a case of several novel species isolated from Neotropical Heteroptera
}

\author{
Vyacheslav Y. Yurchenko, ${ }^{1}$ Julius Lukeš, ${ }^{2}$ Milan Jirkü ${ }^{2}$ \\ and Dmitri A. Maslov ${ }^{3}$ \\ ${ }^{1}$ Albert Einstein College of Medicine of Yeshiva University, Bronx, NY 10461, USA \\ ${ }^{2}$ Biology Center, Institute of Parasitology, Czech Academy of Sciences, and Faculty of Sciences, \\ University of South Bohemia, České Budějovice (Budweis), Czech Republic \\ ${ }^{3}$ Department of Biology, University of California, Riverside, CA, USA
}

\begin{abstract}
Mixed trypanosomatid infections (a simultaneous presence of two or more parasites in the same host) have long been suspected to represent an obstacle for recovering cultures that would faithfully represent original species descriptions. However, without the means to directly compare the parasites in the host and in culture, this would remain just a possibility. Here we have used PCR-based genotyping of spliced leader RNA gene repeats to analyse several novel species of insect trypanosomatids isolated from heteropteran hosts and to compare them with the parasites that had been detected in the gut smears of the same hosts. We have found that, whereas the original infections were dominated by some blastocrithidia-like parasites, most of the respective axenic cultures contained novel species of Crithidia and Leptomonas. Therefore, we concluded that, in each case, this replacement was caused by differences in cultivation properties between the original predominant blastocrithidia and the less fastidious parasite that was later recovered in culture. The properties of the new organisms, including their morphology and ultrastructure, as well as their phylogenetic affinities within the family, were investigated and used to describe five novel species.
\end{abstract}

\section{INTRODUCTION}

Trypanosomatids represent a family of obligate parasites that are capable of parasitizing a variety of insect hosts with frequent occurrence in Heteroptera and Diptera. Flagellates of the genera Trypanosoma and Leishmania found in haematophagous insects are capable of colonizing vertebrates, whereas members of the genus Phytomonas from phytophagous bugs can parasitize plants (Wallace, 1966; Vickerman, 1976; Podlipaev, 1990; Camargo, 1999). The remaining members of the family represent monoxenous insect parasites that are divided among several genera and numerous species. Unlike the aforementioned genera of dixenous parasites, the current morphological classification of monoxenous trypanosomatids, especially at the genus level, has not been supported by recent molecular phylo-

Abbreviations: gGAPDH, glycosomal glyceraldehyde phosphate dehydrogenase; GTR, general time reversible; ML, maximum-likelihood; SL RNA, spliced leader RNA; SSU rRNA, small-subunit rRNA; TU, typing unit; UCR, University of California - Riverside.

The GenBank/EMBL/DDBJ accession numbers for the new sequences determined in this work are given in Table 1. genetic analyses (Simpson et al., 2006). Moreover, recognition and identification of species, described mostly according to the identity of a host, as well as the morphology observed, are generally unreliable. The early realization of the limitations inherent to the traditional approach led to the proposal to augment it with biochemical, molecular and ultrastructural data for characterization of trypanosomatid strains and species, thereby necessitating the use of axenic cultures (Wallace et al., 1983).

The reliance on axenically grown organisms derived from an original infected host creates another set of problems. First, it has become apparent that monoxenous trypanosomatids show significant differences in their cultivation properties and that some of them, especially several Blastocrithidia spp., are particularly difficult to cultivate axenically (Wallace, 1966; Carvalho \& Deane, 1974; Peng \& Wallace, 1981). Thus, the type species of the genus, Blastocrithidia gerridis Patton 1908 emend Laird 1959, has never been cultivated. Cultivation problems were encountered with Leptomonas jaculum, which, in fact, is phylogenetically close to Blastocrithidia triatomae (Kostygov 
\& Frolov, 2007), also a poorly cultivable species (Peng \& Wallace, 1981; Reduth et al., 1989). In recent surveys of trypanosomatid diversity, most of the genotyped organisms that were closely related to the reference Blastocrithidia species were also refractory to axenic cultivation (Maslov et al., 2007). Yet, the same problem was also encountered for other trypanosomatid groups analysed, so it is not generally restricted to a particular group or clade (D. A. Maslov, data not shown).

It was anticipated that an additional problem might be associated with presumed 'mixed' infections (the cases where more than one trypanosomatid species is present simultaneously within the same individual host), especially when the parasites have different cultivation properties (Podlipaev, 2000, 2001). An uncultivable or poorly cultivable organism might be predominant in a natural infection, and its morphology would be used to describe a novel species. Yet, in a culture derived from the infected host this organism would be replaced with another component of the mixed infection, the one that was specifically selected by its higher propensity to cultivation. However, as morphology itself is subject to change during adaptation to the culture conditions, the replacement scenario would remain just one of the possibilities.

Similar problems were encountered with the dixenous species of medical importance (Dukes et al., 1991; Bosseno et al., 2000; Dey et al., 2002). Application of PCR-based techniques showed that mixed infection with up to four different salivarian trypanosomes in the same insect vector are possible (Stevens et al., 1994; Masiga et al., 1996; Jamonneau et al., 2004), and multiple cases of inter- and intraspecies mixed infections have also been reported in animals (Reifenberg et al., 1997; Jamonneau et al., 2004; Njiokou et al., 2004). A selective effect of isolation and cultivation procedures was proposed as being responsible for an apparently low genetic diversity of Trypanosoma brucei (sensu lato) isolated from natural population and infected individuals (Dukes et al., 1991; Stevens et al., 1994; Jamonneau et al., 2002, 2004).

An experimental proof that cultivation can impose a 'bottle-neck' responsible for selection of the best cultivable components from mixed natural trypanosomatid populations would require a comparison of organisms in nature and in culture using objective criteria, such as sequence analysis of an appropriate molecular marker isolated from both stages. We have developed a methodology to analyse spliced leader RNA (SL RNA) gene sequences directly from parasites in insect gut samples (Westenberger et al., 2004; Maslov et al., 2007). Such 'environmental' trypanosomatid sequences were obtained from 60 of 170 species of Neotropical Heteroptera investigated, a number representing a relatively small fraction of all potential hosts. Nearly 48 distinct typing units (TU) (candidate species) were found, almost all of which were new. The SL RNA gene sequences obtained from the gut samples serve as 'barcodes' to identify each of the novel species discovered.
The existence of mixed infections with two or three types of parasites was clearly demonstrated during this survey. The culture-independent analysis was accompanied by several attempts to establish trypanosomatid cultures, but only $40 \%$ of these attempts were successful. By comparing the original environmental SL RNA gene sequences with the culture-derived sequences, we found that most axenic cultures established were authentic. However, several cultures contained trypanosomatid species that were clearly different from organisms found in the original hosts. Herein, we describe the new organisms discovered and discuss the implications of these findings for the development of trypanosomatid classification and phylogeny. As, in most cases, the organisms in culture represented novel species, this discordance could not be explained by trivial factors, such as contamination or culture mix-up. We concluded, therefore, that the original hosts were infected by mixed populations of parasites, and that the organisms recovered in culture were not detected initially due to their relatively low abundance or a bias in the PCRbased procedure, but were selected by their propensity for cultivation at the disadvantage of the other, initially moreabundant but poorly cultivable components.

\section{METHODS}

Organisms and cultures. Insect hosts were collected and dissected as described previously (Westenberger et al., 2004; Maslov et al., 2007). Primary cultures of the parasites were established in the field by inoculating the infected gut material into $1.5 \mathrm{ml}$ Eppendorf tubes filled with $1 \mathrm{ml}$ of SDM79 medium supplemented with antibiotics, as described previously (Westenberger et al., 2004) and by Brun \& Schönenberger (1979). The cultures were then brought to the University of California - Riverside (UCR) laboratory where they were checked regularly by using light microscopy for the presence and propagation of trypanosomatids. Once multiplying organisms were detected, $0.1 \mathrm{ml}$ aliquots of the primary cultures were transferred into $14 \mathrm{ml}$ screw-capped Falcon tubes filled with $10 \mathrm{ml}$ of the medium. This was followed by additional transfers when trypanosomatids became abundant. Contaminating fungi were removed from the cultures with established growth using U-shaped tubes as described previously by Podlipaev \& Frolov (1987). Axenic cultures were maintained in T25-type horizontal flasks filled with $10 \mathrm{ml}$ of the medium without antibiotics.

Microscopy. Cells were processed for light, transmission and scanning electron microscopy as described elsewhere (Yurchenko et al., 2006a, b, 2008).

DNA analyses. Insect gut DNA samples ('environmental' DNA samples) were obtained in the field by placing an aliquot of the gut material in $0.5 \mathrm{ml} 1 \% \mathrm{SDS}, 100 \mathrm{mM}$ EDTA. The material was kept at ambient temperature for 1-3 weeks before transfer to the UCR laboratory, wherein DNA was isolated by using a standard phenol/ chloroform procedure as described previously (Westenberger et al., 2004; Maslov et al., 2007). In addition, the DNA samples were purified with InstaGene matrix (Bio-Rad), according to the manufacturer's protocol. DNA from axenically grown cells was isolated using $10 \mathrm{ml}$ cultures and standard procedures.

PCR amplification of SL RNA gene repeats was performed as described previously (Westenberger et al., 2004; Maslov et al., 2007). Amplification of glycosomal glyceraldehyde phosphate dehydrogenase 
(thereafter referred to as gGAPDH) was done using the oligonucleotide primers M200, 5'-ATGGCTCC $(\mathrm{G} / \mathrm{A} / \mathrm{C})(\mathrm{G} / \mathrm{A} / \mathrm{C}) \mathrm{TCAA}(\mathrm{G} / \mathrm{A})$ GT(A/T)GG(A/C)AT-3' and M201, 5'-TA(G/T)CCCCACTC(G/A) TT(G/A)TC(G/A)TACCA-3', but otherwise followed procedures described previously (Yurchenko et al., 2006a). Amplification of small-subunit rRNA (SSU rRNA) genes was performed as described previously (Yurchenko et al., 2006b). Cloning and sequencing procedures used have also been described previously (Yurchenko et al., 2006a).

Sequences determined in this work were deposited in GenBank with the accession numbers given in Table 1 .

Molecular phylogenetic analyses. Sequences were aligned using CLUSTAL_X, version 1.81 (Thompson et al., 1997). The PCR primer annealing sites were removed from the alignments.

For cluster analysis of the SL RNA gene repeats, the alignment included only the most conserved region encompassing the intron, exon and upstream sequence at positions from -100 to -1 (Westenberger et al., 2004). Neighbour-joining clustering was performed with PAUP ${ }^{*} 4.0$ beta version (Swofford, 1998) using the Kimura two-parameter distances.

The gGAPDH alignment was $1002 \mathrm{nt}$ long and represented the entire sequences; the SSU rRNA gene alignment was $1795 \mathrm{nt}$ long and contained only the most conserved regions that were manually selected from the CLUSTAL-generated alignment. The best-fitting model of sequence evolution was chosen using AIC test implemented with MODELTEST, version 3.06 (Posada \& Crandall, 1998). The general time reversible (GTR) model was selected in both cases, with the parameters: $\mathrm{I}=0.3291$ and $\Gamma=0.6983(\mathrm{gGAPDH})$ or $\mathrm{I}=0.5815$ and $\Gamma=0.6291$ (SSU rRNA gene). Maximum-likelihood (ML), minimumevolution and parsimony analyses of the gGAPDH and SSU rRNA gene datasets were performed using PAUP ${ }^{*} 4.0$ beta version (Swofford, 1998).

The accession numbers of the gGAPDH and SSU rRNA gene sequences retrieved from GenBank were: Blastocrithidia culicis (SSU, U05679), Blastocrithidia triatomae (SSU, AF153037), Bodo saltans K (SSU, AF208889), 'Crithidia deanei' ATCC 30255 (gGAPDH, EF546792), Crithidia fasciculata (gGAPDH, AF047493; SSU, Y00055), Crithidia luciliae (gGAPDH, AF053740), Crithidia oncopelti ATCC 12982 (SSU, AF038025), Endotrypanum monterogeii (SSU, X53911), Herpetomonas muscarum (gGAPDH, DQ092548; SSU, L18872), Herpetomonas pessoai (gGAPDH, AF047494), Herpetomonas roitmani (SSU, AF038023), Herpetomonas ztiplika (SSU, AF416560), Herpetomonas sp. TCC263 (SSU, AF038024), Leishmania amazonensis (SSU, X53912), Leishmania donovani (SSU, X07773), Leishmania guyanensis (SSU, X53913), Leishmania major (gGAPDH, AF047497; SSU, X53915), Leishmania tarentolae (gGAPDH, DQ092549; SSU, M84225), Leptomonas acus (gGAPDH, DQ910926; SSU, DQ910923), Leptomonas bifurcata (gGAPDH, DQ910928; SSU, DQ910925), Leptomonas collosoma (SSU, AF153038), Leptomonas costaricensis (gGAPDH, DQ383650; SSU, DQ383648), Leptomonas jaculum (SSU, EF184218), Leptomonas lactosovorans (gGAPDH, AF053741), Leptomonas podlipaevi (gGAPDH, DQ019000; SSU, DQ383649), Leptomonas pyrrhocoris (gGAPDH, AY029072), Leptomonas seymouri (gGAPDH, AF047495; SSU, AF153040), Leptomonas tarcoles (gGAPDH, EF546787; SSU, EF546786), 'Leptomonas' sp. Cfm (gGAPDH, AF320820; SSU, AF153041), 'Leptomonas' sp. P (gGAPDH, EF546793), Phytomonas sp. (gGAPDH, AF047496), Phytomonas serpens 1G (SSU, AF016323), Phytomonas sp. EM1 (SSU, AF016322), Phytomonas sp. HART1 (SSU, L35076), Sergeia podlipaevi (gGAPDH, DQ394365; SSU, DQ394362), Trypanosoma avium (SSU, U39578), Trypanosoma brucei brucei (gGAPDH, X59955), Trypanosoma cruzi (gGAPDH, X52898),

Table 1. GenBank accession numbers of the new sequences determined in this work

\begin{tabular}{|c|c|c|c|}
\hline Organism & gGAPDH & SL RNA gene repeat & SSU rRNA gene \\
\hline Leptomonas neopamerae sp. nov., 73BR & DQ910927 & EF152332-EF152334 & DQ910924 \\
\hline Leptomonas cf. lactosovorans 37EC & EU076602 & & EU079122 \\
\hline Leptomonas cf. podlipaevi 59LI & EU076604 & EU088271 & EU079124 \\
\hline Crithidia insperata sp. nov., 119YS & EU076605 & EU088272, EU088273 & EU079125 \\
\hline Crithidia abscondita sp. nov., 127AL & EU076606 & EU088274 & EU079126 \\
\hline Wallaceina inconstans & EU076608 & EU088280-EU088282 & \\
\hline Wallaceina brevicula & & EU088277-EU088279 & \\
\hline 'Leptomonas' peterhoffi & & EU088283-EU088285 & \\
\hline Herpetomonas roitmani $\mathrm{TCC} 080$ & EU079130 & EU095978 & \\
\hline Herpetomonas sp. TCC263 & EU079131 & EU095976, EU095977 & \\
\hline Blastocrithidia culicis ATCC 30268 & EU079136, EU079137 & & \\
\hline Phytomonas serpens $1 \mathrm{G}$ & EU084892-EU084894 & & \\
\hline Phytomonas sp. EM1 & EU084895 & & \\
\hline 'Blastocrithidia miridarum' ZM & EU084896, EU084897 & & EU079128 \\
\hline Herpetomonas muscarum & & EU095983-EU095984 & \\
\hline Herpetomonas megaseliae & & EU095979-EU095982 & \\
\hline Leptomonas collosoma & EU084898, EU084899 & & \\
\hline Bodo saltans $\mathrm{K}$ & EU084900, EU084901, EU084902 & & \\
\hline
\end{tabular}


Trypanosoma scelopori (SSU, U67182), Wallaceina brevicula (gGAPDH, AF316620; SSU, AF153045), Wallaceina inconstans (SSU, AF153044) and undescribed trypanosomatid G755 (SSU, U59491). The gGAPDH sequences of Leishmania braziliensis and Leishmania infantum were retrieved from the genome databases www.genedb. org/genedb/lbraziliensis/ and www.genedb.org/genedb/linfantum/, respectively.

\section{RESULTS}

\section{Isolation of axenic cultures and analysis of cell morphology}

Isolate 59LI. Three out of six specimens of Jadera aeola (Heteroptera, Rhopalidae) were found to contain trypanosomatids. As judged by light microscopy of live smears, the parasites were abundant, relatively slowly moving and resembled epimastigotes by virtue of the flexibility of the anterior end. The smears were used to obtain gut DNA samples designated 59LI, 60LI and 72BR. Four 775-783 bp SL RNA gene repeat units amplified from these samples were $97.6-98.7 \%$ identical to each other. These were designated TU15 and this typing unit was associated with Blastocrithidia leptocoridis and several other typing units by using the neighbour-joining cluster analysis as described previously (Maslov et al., 2007). Cultivation was successful only for the parasites in samples 59LI and 60LI. Some dividing parasites were observed initially in the primary 72BR culture but subsequently all the cells died. The axenic 59LI culture was used to isolate DNA and to amplify SL RNA gene repeats (Fig. 1). The 60LI culture was non-axenic and was not analysed further. The sequenced 59LI repeat was 475 bp long and showed no significant similarity (except for the highly conserved exon and intron regions) to the repeat amplified from the respective gut sample. However, the same repeat was $\sim 94 \%$ identical to the repeats from Leptomonas podlipaevi, the main difference being a $19 \mathrm{bp}$ insert just downstream of the intron in the former (data not shown). We have concluded that the cultivated trypanosomatid 59LI is a member of the Leptomonas podlipaevi 'species group', and that it does not represent the blastocrithidia-like organism that was predominant in the infected hosts.

The cells in culture were morphologically quite homogeneous (Fig 2a-c). Most of them were typical thin and elongated promastigotes with a pointed posterior end. These cells resembled long promastigotes, one of the two cell types observed in Leptomonas podlipaevi. The second type, short promastigotes, was not observed among the 59LI cells. The kinetoplast in 59LI cells was invariably located between the nucleus and the flagellum, and the nucleus was located in the central or posterior region of the cell (Fig. 2a). The prominent flagellum always exceeded the cell in size, sometimes being almost twice as long (Fig. 2b, Table 2). On an ultrastructural level, the 59LI cells, as well as those of all the other species described in this study, contained a set of typical features including: (i) complete corset of subpellicular microtubules; (ii)

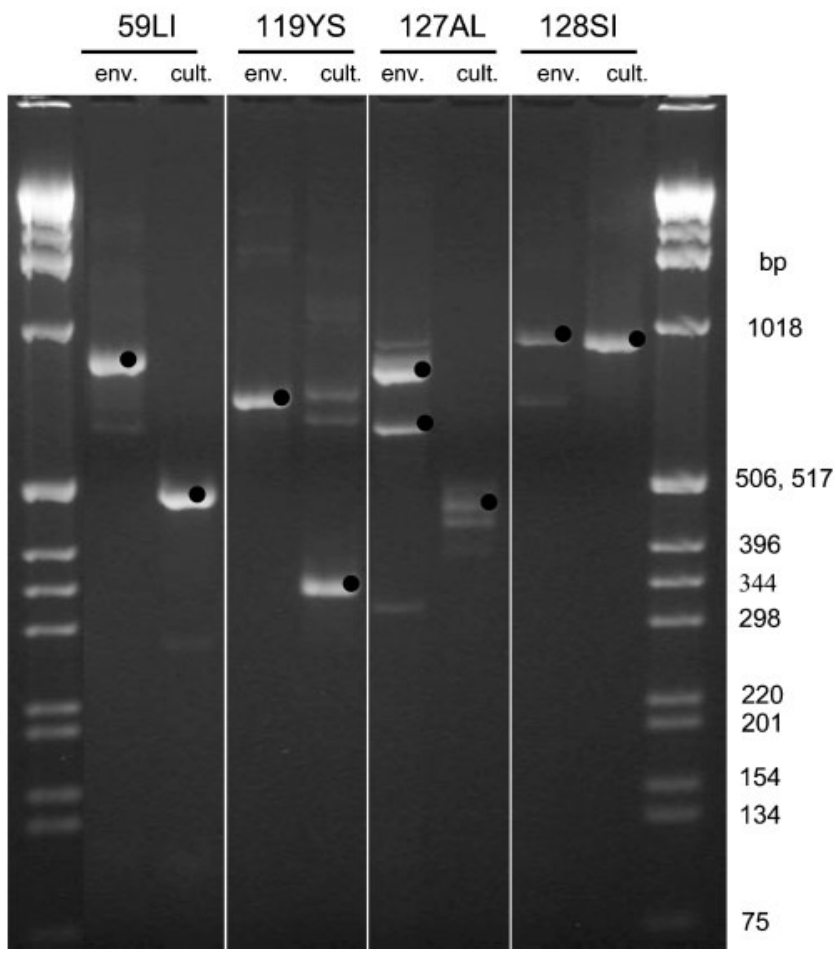

Fig. 1. The juxtaposition of PCR-amplified SL RNA gene repeats from environmental DNA samples (env.) representing infected insect gut material with PCR products obtained using DNA extracted from the axenic cultures (cult.) derived from the respective infected insect hosts. The bands marked with 'dots' contain DNA that was cloned and sequenced. The flanking lanes show a $1 \mathrm{~kb}$ DNA ladder (Invitrogen).

prolonged mitochondrion mostly located just below the cellular membrane and sometimes reticulating, with a low number of small scattered cristae; (iii) nucleus with dense nucleoplasm and nucleolus located at the periphery and centre, respectively; (iv) kinetoplast of specific average dimensions (Table 3); (v) single flagellum with a specific length range (Table 2); (vi) acidocalcisomes of varying morphology, size and abundance; and (vii) inconspicuous glycosomes and endoplasmic reticulum. Overall, the ultrastructure provided only few characteristic features for strain 59LI, in addition to the inconspicuous and relatively shallow flagellar pocket, the thin kinetoplast disk and a low number of small acidocalcisomes (Fig. 2c). The surface of the cells was subtly furrowed.

Isolate 128SI. TU28 was established previously by using a neighbour-joining clustering of repeats from the Ecuadorian isolates $83 \mathrm{AL}, 85 \mathrm{AL}, 86 \mathrm{AL}$ and $88 \mathrm{JS}$, representing four infected (out of nine tested) specimens belonging to three Zoreva species (Heteroptera, Coreidae), as well as the isolates $128 \mathrm{SI}$ and $135 \mathrm{MD}$ from two different species of the tribe Mirini (Heteroptera, Miridae) (Maslov et al., 2007). The 789-812 bp sequences were $\sim 96 \%$ 
identical except for the $16 \mathrm{bp}$ insertion in the 83AL repeats located just downstream of the intron. At least some cells in the insect hosts resembled epimastigotes (especially in 128SI), whereas most were fast moving promastigotes. Culture was attempted only from isolate 128SI. The SL RNA gene repeat amplified from the axenic 128SI culture was $859 \mathrm{nt}$ long (Fig. 1) and only $42.9 \%$ identical to its environmental counterpart, lacking the $5 \mathrm{~S}$ gene found in the latter (data not shown). While the environmental sequences of TU28 were related to Blastocrithidia leptocoridis (Maslov et al., 2007), the axenic culturederived 128SI sequence was rather unique. We therefore concluded that the organism recovered in culture represented a trypanosomatid species that was different from TU28.

Giemsa and DAPI staining revealed substantial heterogeneity in size and shape of the cells in culture, which ranged from droplet-like and oval promastigotes to sphaeromastigotes or choanomastigotes (Fig. $2 \mathrm{~d}$ and e). The kinetoplast was frequently positioned lateral to the nucleus (Fig. 2d and e), and the relatively deep flagellar pocket was then non-concentrically placed (Fig. 2g). A flagellar swelling with desmosomes was obvious at the exit of the flagellum from the flagellar pocket (Fig. $2 \mathrm{~g}$ ), as reported previously for C. fasciculata (Brooker, 1971). The surface of the cell was smooth (Fig. 2f). Acidocalcisomes were relatively rare. Thus, according to the current classification, the cultured 128SI cells represent a novel species of Crithidia.

Isolate 119YS. A specimen of Leptopetalops sp. (Heteroptera, Coreidae) in Ecuador was found to contain abundant epimastigote- and promastigote-like cells (sample 119YS) (Maslov et al., 2007). The two 650 bp SL RNA gene repeats amplified from this sample differed from each other only by a single nucleotide, and were previously designated TU37 that grouped with the major Blastocrithidia leptocoridis-Blastocrithidia triatomae clade (Maslov et al., 2007). However, in the axenic culture that was derived from this specimen, the two amplified sequenced monomeric repeats were of 297 and $302 \mathrm{bp}$ (Fig. 1) and were quite dissimilar from the environmental DNA repeats or any other sequences, clearly representing a unique organism.

The morphology of the cells was rather uniform, most of them being barley-shaped choanomastigotes (Fig. 2h) with some of them showing a typical collar-like extension (not shown) as observed in C. fasciculata (Brooker, 1971). Based on the cell morphology, this new organism should thus be allocated within the genus Crithidia. The kinetoplast was often (but not always; Fig. 2l) located immediately adjacent to the centrally located oval nucleus (Fig. $2 \mathrm{~h}$, i and $\mathrm{m}$ ). The conspicuous longitudinal furrows covering the entire surface were visible using transmission electron microscopy (Fig. $2 \mathrm{j}$ and $\mathrm{k}$ ). Both acidocalcisomes and glycosomes are abundant and very visible (Fig. $2 \mathrm{l}$ and data not shown).
Isolate 127AL. The major Blastocrithidia leptocoridisBlastocrithidia triatomae clade also includes two organisms represented by TU45 and TU30, both of which were derived from a single infected specimen of Largus sp. (Heteroptera, Largidae) in Ecuador (sample 127AL) (Maslov et al., 2007). These typing units were characterized by 590 and 786 bp SL RNA gene repeats, respectively. TU30 also included a 785 repeat derived from sample 92JS, which was isolated from a predatory bug Zelus sp. (Heteroptera, Reduviidae) in Ecuador (Maslov et al., 2007). Remarkably, the axenic culture derived from the same infected Largus specimen yielded a third genotype characterized by a somewhat heterogeneous set of 400$500 \mathrm{bp}$ repeats (Fig. 1). The amplified and sequenced repeat from the axenic culture was $458 \mathrm{bp}$ long and bore little similarity to the repeats derived from the gut sample (data not shown). Thus, the organism recovered in culture was different from two major infection components revealed by using a culture-independent approach.

Short barley-shaped choanoflagellates of the 127AL culture were morphologically uniform and resembled the cells of isolate 119YS, with a prominent flagellar pocket visible even in Giemsa-stained cells (Fig. 2n). In the majority of cells, the kinetoplast was virtually juxtaposed to the nucleus (Fig. 2n, o and r). A characteristic feature was the prominent flagellar 'swelling' that occurred at the exit region inside the rather deep flagellar pocket (Fig. $2 \mathrm{q}$ and $\mathrm{r})$. The furrows on the surface of the cells were less prominent than in isolate 119YS (Fig. 2p). Prominent acidocalcisomes were located in the posterior region of the cell. The cultivated organism has to be associated with the genus Crithidia.

In contrast with the cases described above, additional cultivable organisms encountered in the course of this study matched the respective host infections.

Isolate 34EC. Two out of three specimens of Jadera obscura (Heteroptera, Rhopalidae) in Costa Rica contained promastigotes that were used to obtain environmental DNA samples 34EC and 35EC. The amplified SL RNA gene repeats were 514 bp long and represented TU2, which was related to Leptomonas podlipaevi (Maslov et al., 2007). Cultures were obtained in both cases and a single SL RNA gene repeat amplified from the axenic 34EC culture was also 514 bp long and $96.9 \%$ identical to the environmental $34 \mathrm{EC}$ and 35EC sequences, confirming that the culture did represent the TU2 organisms detected in the gut samples (data not shown). The repeats shared only $65 \%$ identity with the 455-457 bp repeats from Leptomonas podlipaevi, indicating that TU2 represents a different organism.

The cells in culture were typical of Leptomonas, represented by promastigotes of uniform cylindrical shape with both ends slightly and equally tapered (Fig. $2 s$ and t). The kinetoplast was always present in the region between the basal body of the flagellum and the centrally located oval nucleus (Fig. $2 \mathrm{~s}$ and t). Scanning electron microscopy 


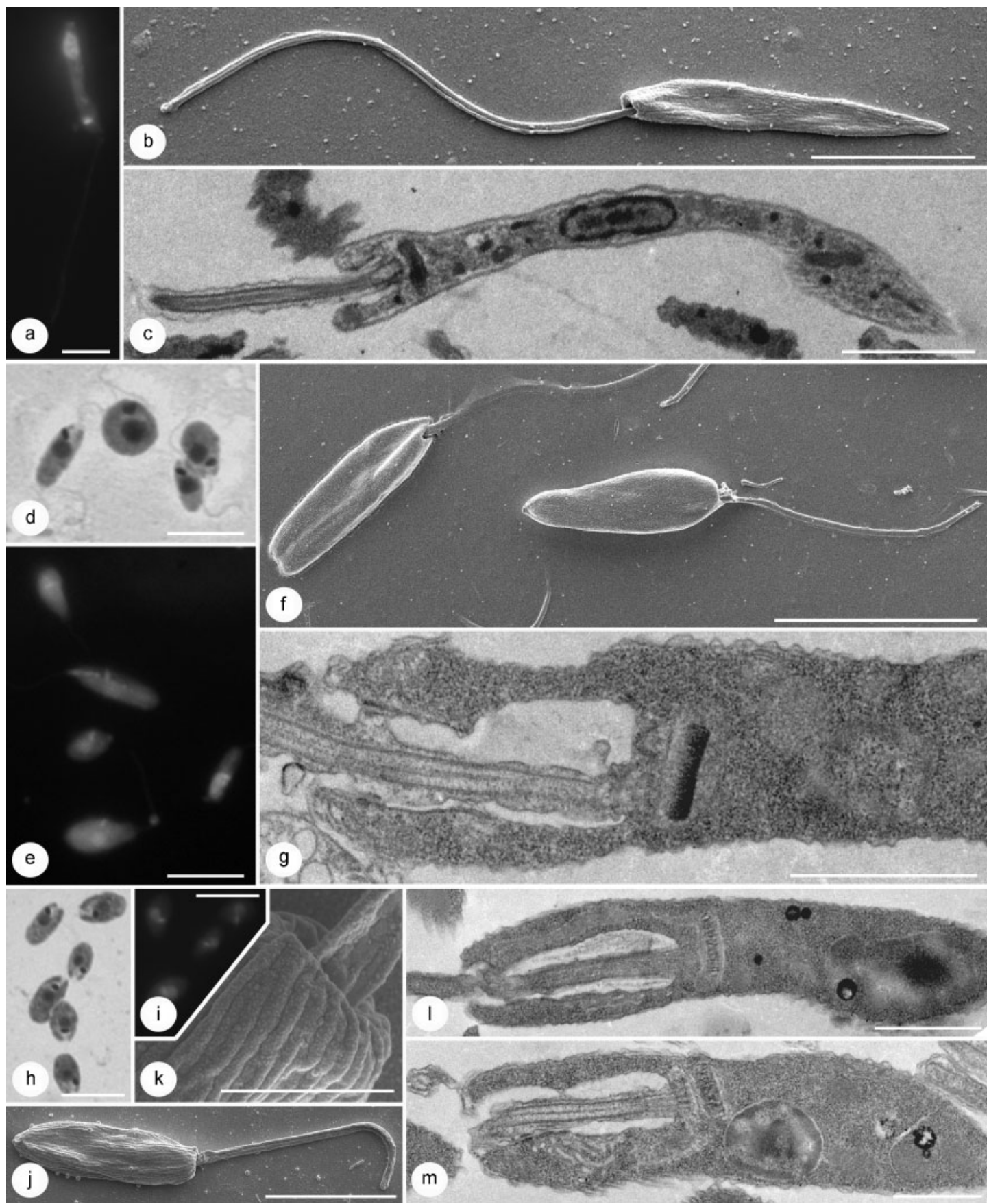

Fig. 2. Morphological and ultrastructural characterization of the cultured trypanosomatids of the isolate Leptomonas cf. podlipaevi $59 \mathrm{LI}(\mathrm{a}-\mathrm{c})$, Crithidia permixta sp. nov. $128 \mathrm{SI}(\mathrm{d}-\mathrm{g})$, Crithidia insperata sp. nov. 119YS (h-m), Crithidia abscondita sp. nov. 127AL $(n-r)$, Leptomonas jaderae sp. nov. 34EC (s-v), Leptomonas neopamerae sp. nov. 73BR (w-b') and Leptomonas cf. lactosovorans 37EC $\left(c^{\prime}-f^{\prime}\right)$. The panels represent DAPI-stained (a, e, h, o, t, x, d') and Giemsa-stained (d, h, n, $\left.s, w, c^{\prime}\right)$ cells, scanning electron microscopy images (b, f, j, k, p, u, y, z, e') and transmission electron microscopy images of cross-sectioned cells (c, g, l, m, q, r, v, a', b', f'). Bars, $500 \mathrm{~nm}(\mathrm{k}), 1 \mu \mathrm{m}\left(\mathrm{g}, \mathrm{l}, \mathrm{m}, \mathrm{v}, \mathrm{a}^{\prime}, \mathrm{b}^{\prime}, \mathrm{f}^{\prime}\right), 2 \mu \mathrm{m}\left(\mathrm{c}, \mathrm{q}, \mathrm{r}, \mathrm{z}, \mathrm{e}^{\prime}\right), 5 \mu \mathrm{m}(\mathrm{a}, \mathrm{b}, \mathrm{j}, \mathrm{p}$, $w, x, y)$ and $10 \mu m\left(d, e, f, h, i, n, o, s, t, u, c^{\prime}, d^{\prime}\right)$. 


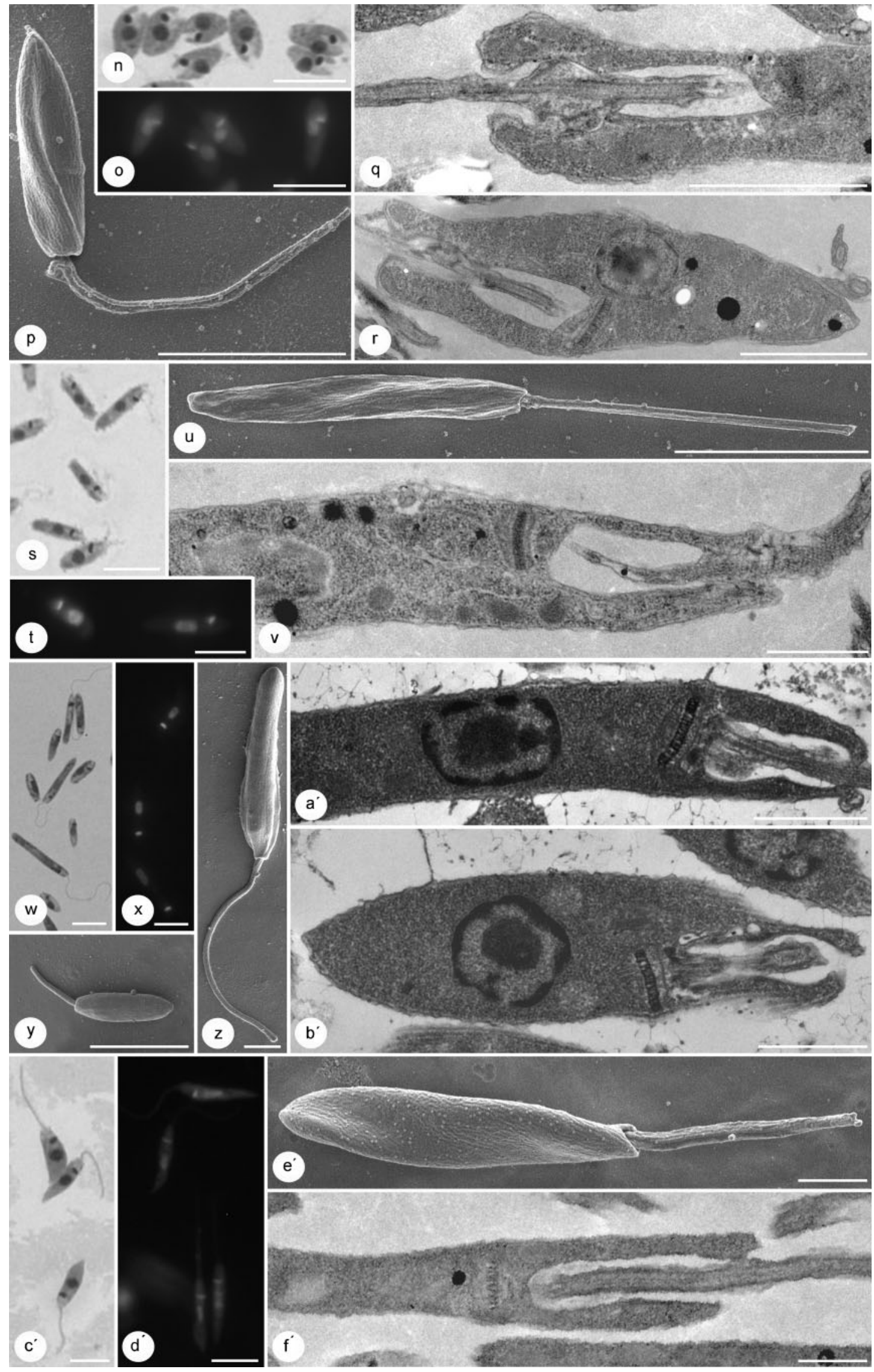


Table 2. Morphometry of cells in the cultures isolated showing the observed range

Values in parentheses are means $\underline{\mathrm{SD}}(n=50)$.

\begin{tabular}{|llccc|}
\hline Strain & Total length $(\boldsymbol{\mu m})$ & Nucleus to kinetoplast $(\boldsymbol{\mu m})$ & Nucleus to posterior end $(\boldsymbol{\mu m})$ & Length of flagellum $(\boldsymbol{\mu m})^{\star}$ \\
\hline 59LI & $7.9-15.6(11.9 \pm 1.6)$ & $0.3-1.1(0.7 \pm 0.2)$ & $2.7-8.6(5.2 \pm 1.7)$ & $11.4-24.3(7.8 \pm 2.9)$ \\
128SI & $6.2-10.5(7.7 \pm 0.8)$ & $0.4-1.8(0.8 \pm 0.3)$ & $2.0-3.9(2.7 \pm 0.5)$ & $7.1-16.3(10.2 \pm 1.9)$ \\
$119 \mathrm{YS}$ & $6.0-8.5(7.2 \pm 0.7)$ & $0.2-1.2(0.7 \pm 0.2)$ & $2.0-4.6(3.0 \pm 0.5)$ & $7.8-12.5(10.0 \pm 1.1)$ \\
127AL & $5.7-8.1(6.9 \pm 0.6)$ & $0.4-1.2(0.8 \pm 0.2)$ & $1.8-3.4(2.5 \pm 0.4)$ & $7.2-1.5(9.2 \pm 0.9)$ \\
34EC & $6.1-10.7(8.9 \pm 1.1)$ & $0.6-1.7(1.2 \pm 0.3)$ & $1.6-5.2(3.3 \pm 0.6)$ & $4.4-9.8(7.7 \pm 1.2)$ \\
73BR & $4.4-12.7(7.1 \pm 2.0)$ & $0.4-2.5(1.0 \pm 0.5)$ & $1.1-5.6(2.5 \pm 1.0)$ & $8.9-17.8(7.7 \pm 1.2)$ \\
37EC & $7.6-12.9(10.0 \pm 1.0)$ & $0.7-1.8(1.2 \pm 0.2)$ & $3.1-5.7(4.3 \pm 0.7)$ & $8.7-14.2(11.1 \pm 1.3)$ \\
\hline
\end{tabular}

${ }^{\star}$ Cells with no or very short flagella were excluded from the measurements.

revealed a slight (half-turn or less) twist in most cells and fine furrows on their surface (Fig. $2 \mathrm{u}$ ). The thin kinetoplast disk was usually located next to the relatively shallow but wide flagellar pocket (Fig. 2v).

Isolate 73BR. One of four specimens of Neopamera sp. (Heteroptera, Lygaeidae) in Costa Rica (isolate 73BR) and one of 12 Neopamera costalis in Ecuador (isolate 82AL), all collected by using a light trap, were infected with a novel trypanosomatid species that was designated TU26 (Maslov et al., 2007). The parasites in insects were promastigotes characterized by a relatively long slender shape. The sequences of SL RNA gene repeats obtained from both environmental DNA samples belonged to two size classes: the 198 bp class A and 235-238 bp class B. The difference in size was due mainly to an insertion/deletion in the intergenic region (Maslov et al., 2007). An axenic culture was obtained for isolate 73BR, and the same set of SL RNA gene repeats was amplified from the culture as from the environmental samples, thereby confirming that the culture faithfully represents the original infection (data not shown). The sequences of the three individual class A repeats analysed were $88.4-100 \%$ identical to the respective environmental sequences. All sequenced Aand B-class repeats clustered together using the neighbour-joining analysis (see below; Fig. 3).

Table 3. Dimensions of the kinetoplast disk

Values are means $\pm \mathrm{SD}$.

\begin{tabular}{|lccc|}
\hline Strain & Thickness $(\mathbf{n m})$ & Width $(\mathbf{n m})$ & $\boldsymbol{n}$ \\
\hline 59LI & $104 \pm 32$ & $680 \pm 113$ & 10 \\
128SI & $151 \pm 21$ & $800 \pm 150$ & 24 \\
119YS & $184 \pm 63$ & $703 \pm 128$ & 31 \\
127AL & $172 \pm 29$ & $818 \pm 182$ & 23 \\
34EC & $95 \pm 12$ & $757 \pm 173$ & 20 \\
73BR & $89 \pm 14$ & $673 \pm 142$ & 34 \\
37EC & $114 \pm 15$ & $681 \pm 117$ & 18 \\
& & & \\
\hline
\end{tabular}

The cells were typical of Leptomonas with a rod-shaped promastigote body that, however, varied markedly in length (Fig. $2 \mathrm{w}$ ). As for the size of the cell, the length of the flagellum was also highly variable (Fig. $2 y$ and $z$ ), and the extending flagellum was absent or very short in approximately $80 \%$ of cells. The kinetoplast was never found to be in close proximity to the centrally positioned oval nucleus (Fig. 2x), but was rather at some distance as shown in longitudinal sections of long (Fig. 2a') and short promastigotes (Fig. $2 \mathrm{~b}^{\prime}$ ). The flagellar pocket was relatively shallow (Fig. 2a' and $\mathrm{b}^{\prime}$ ). The kinetoplast, located immediately next to the basal body of the flagellum, was relatively thin (Table 3 ), testifying to the small size of kinetoplast DNA minicircles (Lukeš \& Votýpka, 2000; Yurchenko \& Kolesnikov, 2001). Another characteristic feature of this flagellate was the presence of only very few and small, round acidocalcisomes with even electron-dense contents (data not shown).

Isolate 37EC. A trypanosomatid infection was detected in a specimen of Pachygrontha barberi (Heteroptera, Lygaeidae) from Costa Rica. The parasites represented abundant free and highly motile promastigotes. Attempts to amplify the SL RNA gene repeats from the environmental sample using PCR failed repeatedly, whereas the gGAPDH gene could be amplified from the same sample. An axenic culture was established, but no SL RNA gene amplification product was obtained using the culture DNA. Other phylogenetic markers, such as gGAPDH and SSU rRNA gene, were amplifiable from the cell culture, indicating that the problem lay specifically with the SL RNA gene repeats in this organism. Almost identical gGAPDH gene sequences were amplified from the infected gut material and from the axenic culture (data not shown), indicating a match of the culture and the original infection. The respective sequences were almost identical to the partial gGAPDH sequence of Leptomonas lactosovorans, isolated previously from a reduviid Zelurus martinsi in Brazil (Manaia et al., 1981).

Typically, the cells were flattened and slightly twisted promastigotes with a relatively short and thick flagellum 
(Fig. $2 \mathrm{c}^{\prime}$ and $\mathrm{e}^{\prime}$ ). In Giemsa- and DAPI-stained smears, the cells invariably had a round, centrally located nucleus to which the kinetoplast was never adjacent (Fig. $2 c^{\prime}$ and $d^{\prime}$ ). Using scanning electron microscopy, a very characteristic surface could be visualized, covered by an elaborate mesh of furrows (Fig. 2 $\mathrm{e}^{\prime}$ ) that was visible using transmission microscopy as undulations of the cell membrane (Fig. $2 \mathrm{f}^{\prime}$ and data not shown). The flagellar pocket was deep, its opening was never blunt ended, the kinetoplast disk was inconspicuous and thin, and the electron-dense acidocalcisomes were numerous and prominent (Fig. $2 \mathrm{f}^{\prime}$ ). According to the current morphology and consistent with the aforementioned gGAPDH sequence data, the isolate has to be designated Leptomonas, although additional analyses are necessary to see whether it is identical to Leptomonas lactosovorans.

\section{SL RNA gene-based genotyping of the new organisms}

For the preliminary assessment of the relationships of the isolated organisms with other members of the family we used a neighbour-joining cluster analysis of the SL RNA gene repeats. The resolving power of the method is very high and allows closely related organisms to be distinguished, whereas more slowly evolving markers are used to analyse the higher order relationships. More than 200 individual SL RNA gene repeat sequences were selected to represent most of the species of monoxenous insect trypanosomatids analysed and the recently characterized new typing units, as well as representative members of the dixenous genera Leishmania, Trypanosoma and Phytomonas. This set was supplemented with sequences from the new isolates and several named species as listed in Table 1. Only the most conserved sequence regions of the repeat were used in the analysis, including the exon and intron and the upstream $100 \mathrm{bp}$. As even these sections could not be unambiguously aligned across the entire dataset, because of the rapid evolution of the SL RNA gene repeats, the results of such an analysis should not be overinterpreted, as noted above.

A dendrogram summarizing the results of the analysis is shown in Fig. 3. Only the terminal and subterminal clades were recovered in the bootstrap majority consensus tree, which otherwise represented a major polytomy (not shown). As expected, the isolates 34EC and 73BR clustered together with the corresponding environmental sequences designated TU2 and TU26, respectively. A well-separated cluster was observed in each case, indicating that each of these typing units merits the status of a separate novel species. The respective SL RNA gene repeat sequences could serve as unique 'barcodes' associated with these species.

In contrast, the dendrogram positions of the axenic culture-derived 59LI, 119YS, 127AL and 128SI sequences were different from their environmental counterparts, all of which belonged to the large 'Blastocrithidia triatomae-
Blastocrithidia leptocoridis' clade. While the cultivated 59LI sequence clustered together with Leptomonas podlipaevi, each of the remaining sequences (119YS, 127AL and 128SI) was found to occupy a separate position in the dendrogram. Therefore, these three axenic cultures obviously represented novel trypanosomatid species, each uniquely 'barcoded' with the respective SL RNA gene repeat sequence.

\section{Phylogenetic associations of the novel species}

In order to more accurately position the novel species within the family, we used phylogenetic analysis of the GADPH and SSU rRNA gene sequences amplified from the axenically grown cells. The trees were rooted using the sequences of Bodo saltans, the closest known outgroup to Trypanosomatidae (Doležel et al., 2000; Simpson et al., 2000). Besides the maximally fully represented 'SE' clade, the analyses included other known major clades of the Trypanosomatidae, each represented by a few relatively slowly evolving members (Hollar et al., 1998; Lukeš et al., 1997; Merzlyak et al., 2001). The overall tree topologies (Figs 4 and 5) were similar to those in previous phylogenetic analyses (Yurchenko et al., 2006a, b, 2008) and are not discussed herein. It is only important to mention that, although a single gene analysis allows wellsupported clades of trypanosomatids to be revealed, it fails to resolve all deep-branching relationships, which remain a task for the future.

Most of the novel isolates were found in the clade that also contains the majority of monoxenous trypanosomatids (previously denoted as 'SE' clade) (Merzlyak et al., 2001). Isolate 59LI, as expected on the basis of the SL RNA gene sequence comparisons, was close to Leptomonas podlipaevi. These two, along with the novel species represented by isolates $34 \mathrm{EC}$ and $73 \mathrm{BR}$, and the 'old' (described many years ago) species Leptomonas seymouri and Leptomonas pyrrhocoris, formed a well-supported clade 'L2'.

The phylogenetic affinities of the novel isolates 119YS, $127 \mathrm{AL}$ and $128 \mathrm{SI}$ were not unquestionably resolved. Isolate 119YS showed a clear tendency to associate with Leptomonas bifurcata and the species currently designated 'C. deanei' ATCC 30255 in the gGAPDH analysis, but this relationship was not strongly supported using the SSU rRNA gene bootstrap analysis. A similar relationship can be traced between isolate 128SI and 'Leptomonas' sp. Cfm but this does not withstand all the tests. Isolate $127 \mathrm{AL}$ was found in different positions depending on the marker and the method used, albeit invariably within the 'SE' clade, as the other two isolates. The 37EC gGAPDH sequence was found within clade ' $\mathrm{H}$ ', which contains several typical Herpetomonas species, as well as the sequence of Leptomonas lactosovorans.

In the present analysis we also investigated two endosymbiont-containing species, 'C. deanei' (strain ATCC 30255) and C. oncopelti (strain ATCC 12982), as well as their alleged endosymbiont-free derivatives (C. deanei ATCC 30969 and 


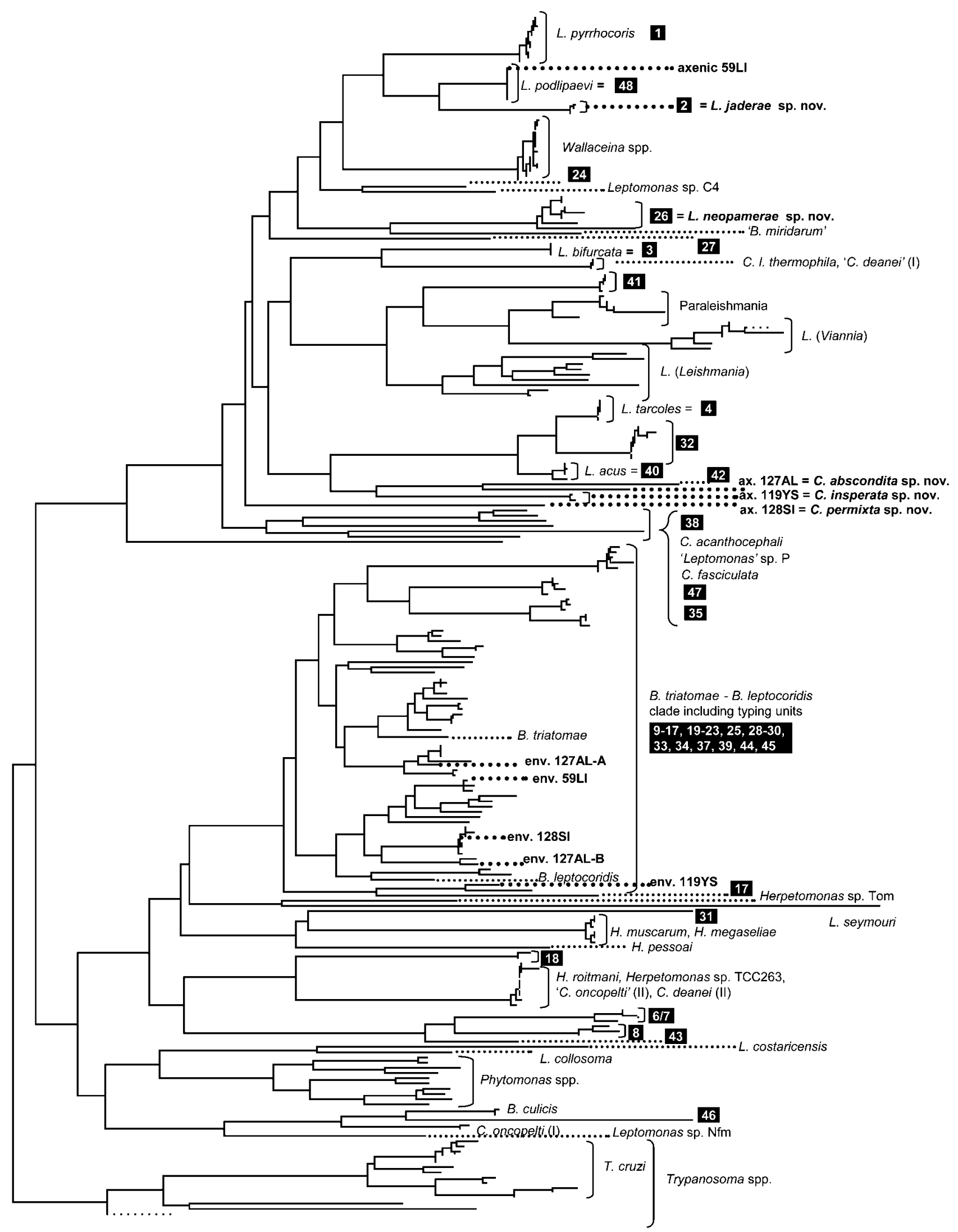


Fig. 3. Neighbour-joining analysis of the partial (from the -100 position to the $3^{\prime}$-end of the intron) sequences of the SL RNA gene repeats from the axenic cultures (ax.) representing isolates $59 \mathrm{LI}$ (=Leptomonas cf. podlipaevi), 119YS (=C. insperata sp. nov.), 127AL (=C. abscondita sp. nov.), 128SI (=C. permixta sp. nov.) and the respective insect gut samples (env.). The dendrogram also contains sequences representing trypanosomatid typing units TU1 to TU48, shown by numbers in boxes, as well as a set of reference trypanosomatid species used previously (Maslov et al., 2007; Westenberger et al., 2004) and supplemented with the sequences determined in this work (Table 1). 'C. deanei' (I) represents the strain ATCC 30255, C. deanei (II) - the strain ATCC 30969, C. oncopelti (I) - ATCC 12982, 'C. oncopelti' (II) - ATCC 30264. The clade of the Wallaceina species also includes the sequences from 'Blastocrithidia gerricola', 'Leptomonas peterhoffi', 'Leptomonas' sp. F2, 'Leptomonas' sp. F5 and 'Leptomonas' sp. F6. The use of parentheses indicates that the organism in culture does not match the original description.

'C. oncopelti' ATCC 30264). Remarkably, in each case the original endosymbiont-bearing strain and its putative derivative turned out to be different organisms. Moreover, while the former was clearly unique, the latter was virtually indistinguishable from $H$. roitmani, both by gGAPDH, SSU rRNA gene and SL RNA gene sequence analyses. Also, the phylogenetic position of the supposedly endosymbiontbearing ' $C$. deanei' strain ATCC 30255 was very distant from the other endosymbiont-containing trypanosomatids. The investigation of this strain using light and electron microscopy (data not shown) has demonstrated that it indeed lacks endosymbionts, contrary to what was expected for the authentic strain (Gadelha et al., 2005).

\section{Taxonomic section}

The analyses described above provide a justification for the recognition of the two novel Leptomonas species (represented by isolates 34EC and 73BR) and the three novel Crithidia species (isolates 119YS, 127AL and 128SI). The two remaining isolates, 59LI and 37EC, were very close or identical phylogenetically to the previously recognized species, Leptomonas podlipaevi and Leptomonas lactosovorans, respectively, and therefore, do not merit a separate species status. In the absence of a natural taxonomic system for Trypanosomatidae, we have adopted the traditional genus-level classification (Hoare \& Wallace, 1966; Wallace, 1966; Vickerman, 1976).

Class Kinetoplastea Honigberg 1963 emend. Vickerman 1976

Subclass Metakinetoplastina Vickerman 2004

Order Trypanosomatida Kent 1880 stat. nov. Hollande 1952

Family Trypanosomatidae Doflein 1951

\section{Leptomonas jaderae sp. nov. Maslov and Lukeš}

Genus assignment. The typical promastigote morphotype of the cells was the basis for the assignment of the novel species to the genus Leptomonas Kent 1880. This classification is consistent with the gGAPDH phylogeny, which shows that the organism belongs to the clade (L2; Fig. 4) composed of three typical Leptomonas species (Leptomonas podlipaevi, Leptomonas seymouri and Leptomonas pyrrhocoris) and is more closely related to
Leptomonas podlipaevi. This relationship was also confirmed by the SL RNA and SSU rRNA gene analyses (Figs 3 and 5).

Specific characters. Cells are medium size, typical promastigotes, rather uniform in length, with few morphological peculiarities. However, Leptomonas jaderae sp. nov. can be easily distinguished from related species by the characteristic sequences of the SL RNA gene repeats (514 bp; GenBank accession numbers EU088270, DQ860221, DQ860222), as well as by its gGAPDH and SSU rRNA gene sequences.

Type host. Intestine of Jadera obscura (Heteroptera, Rhopalidae). The xenotype (the post-dissection host remains) is stored in the UCR Entomology Museum (UCRC ENT 126517).

Type locality. In the vicinity of Tárcoles $\left(09^{\circ} 45^{\prime} 24^{\prime \prime} \mathrm{N} 84^{\circ}\right.$ $36^{\prime} 42^{\prime \prime}$ W), Province Puntarenas, Costa Rica.

Type material. The hapantotype represents the type culture of isolate 34EC stored in the American Type Culture Collection (ATCC PRA-264), and in the collection of the Institute of Parasitology (Budweis, Czech Republic).

Etymology. The species name was chosen based on the host genus name.

\section{Leptomonas neopamerae sp. nov. Maslov and Lukeš}

Genus assignment. The organism belongs to the genus Leptomonas Kent 1880 based on the morphology of the promastigotes of cells in culture and nature. The organism is most closely related to the Leptomonas species $L$. podlipaevi, L. seymouri, L. pyrrhocoris and L. jaderae sp. nov.

Specific characters. Most cells in culture are mediumsized cylindrical promastigotes. A large fraction of cells in culture (up to $70 \%$ ) has no visible flagellum, yet they are still elongated. This organism is distinguished from the other species mainly phylogenetically (gGAPDH, SSU rRNA gene sequences) and by the presence of two related classes (198 and 235-238 bp) of SL RNA gene repeats with characteristic sequences (EF152332-EF152334, DQ864326, DQ864288 and DQ864289). 


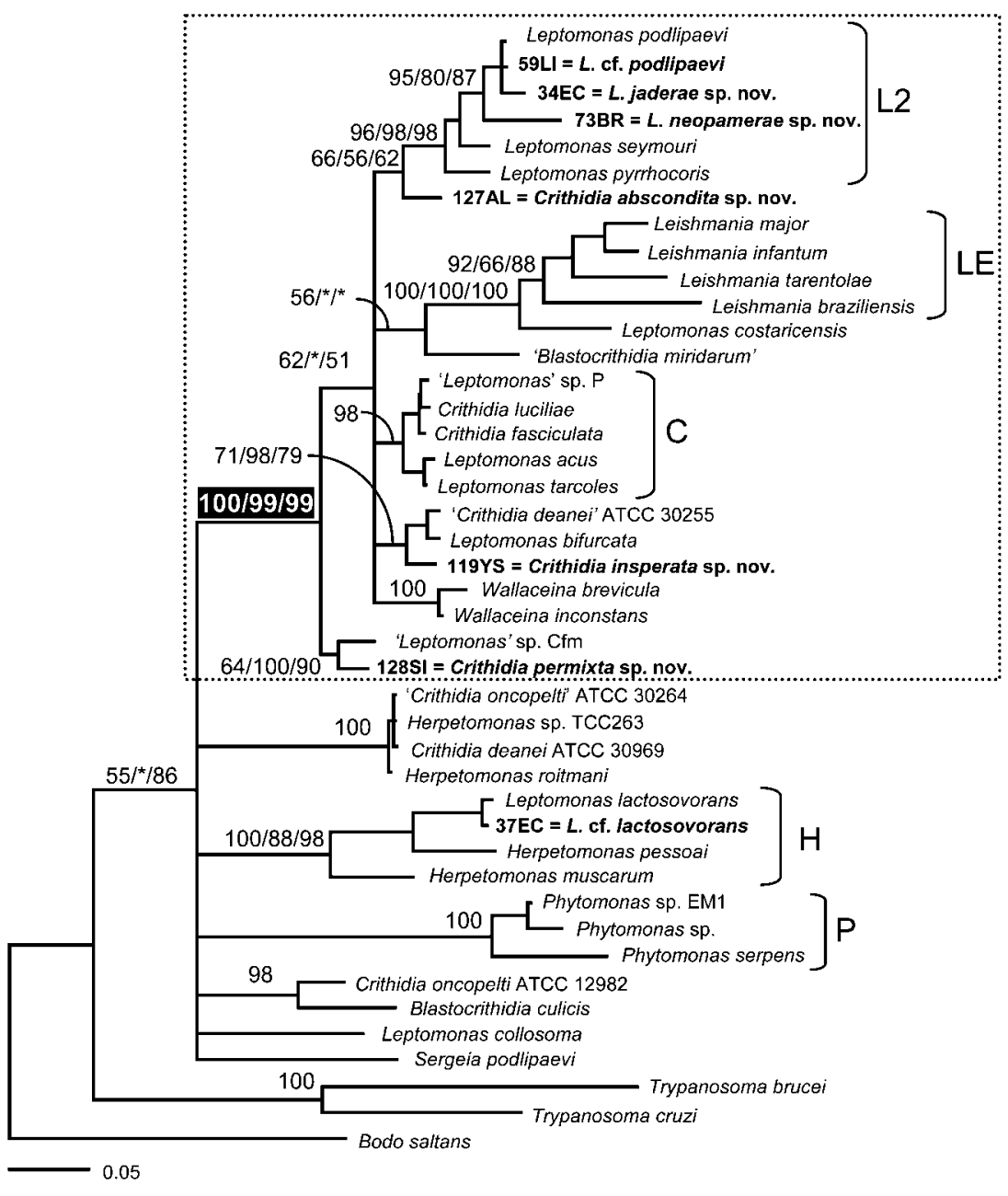

Fig. 4. gGAPDH gene phylogenetic analysis of the novel trypanosomatid species. The percentage bootstrap values in the consensus $\mathrm{ML}$ tree ( $L n$-likelihood $=-10545.46573)$ were derived after 100 replicates. Other values shown represent minimum evolution (the second value, 1000 replicates) and parsimony analyses (the third value, 1000 replicates). Asterisks denote the nodes that were recovered in less than $50 \%$ of replicates. Clade designations ( $L E, L 2, C, P$ and $H$ ) follow our previous nomenclature (Yurchenko et al., 2006a). Bar, 0.05 substitutions per site. The best ML tree (not shown, $L n$-likelihood $=-10484.59354$ ) was derived by a heuristic search with the GTR $+\mathrm{I}+\Gamma$ model $(\mathrm{I}=0.3291$ and $\Gamma=0.6983)$.
Type host. Intestine of Neopamera sp. (Heteroptera: Lygaeidae). The xenotype - UCRC ENT 140280.

Type locality. In the vicinity of Dominical $\left(09^{\circ} 15^{\prime} \mathrm{N} 83^{\circ}\right.$ $52^{\prime}$ W), Province Puntarenas, Costa Rica.

Type material. The hapantotype - the type culture of the isolate 73BR (ATCC PRA-215), also stored in the collection of the Institute of Parasitology (Budweis, Czech Republic).

Etymology. The species name reflects the findings of this trypanosomatid in two species of Neopamera from Costa Rica and Ecuador.

\section{Crithidia insperata sp. nov. Maslov and Lukeš}

Genus assignment. The predominant morphology in culture is that of typical choanomastigotes resembling those of $C$. fasciculata, hence the assignment to the genus Crithidia Léger 1902.

Specific characters. The general morphology is that of typical endosymbiont-free crithidias. The cell surface is covered with relatively deep furrows. The novel species is unquestionably separated from other species with a similar morphology by the unique sequences 297-302 SL RNA gene repeats (EU088272, EU088273), as well as gGAPDH and SSU rRNA genes.

Type host. Intestine of Leptopetalops sp. (Heteroptera, Coreidae). The xenotype - UCRC ENT 138406.

Type locality. Yasuni National Park $\left(00^{\circ} 40^{\prime} 27^{\prime \prime}\right.$ S $76^{\circ} 23^{\prime}$ $\left.49^{\prime \prime} \mathrm{W}\right)$, Province Napo, Ecuador.

Type material. The hapantotype - the type culture of 119YS (ATCC PRA-263), also stored in the collection of the Institute of Parasitology (Budweis, Czech Republic).

Etymology. This organism was unanticipated ('insperatus' in Latin) in the culture that was derived from the Blastocrithidia-dominated infection in the original host.

\section{Crithidia abscondita sp. nov. Maslov and Lukeš}

Genus assignment. The organism represents a member of the genus Crithidia Léger 1902 in accordance with the 


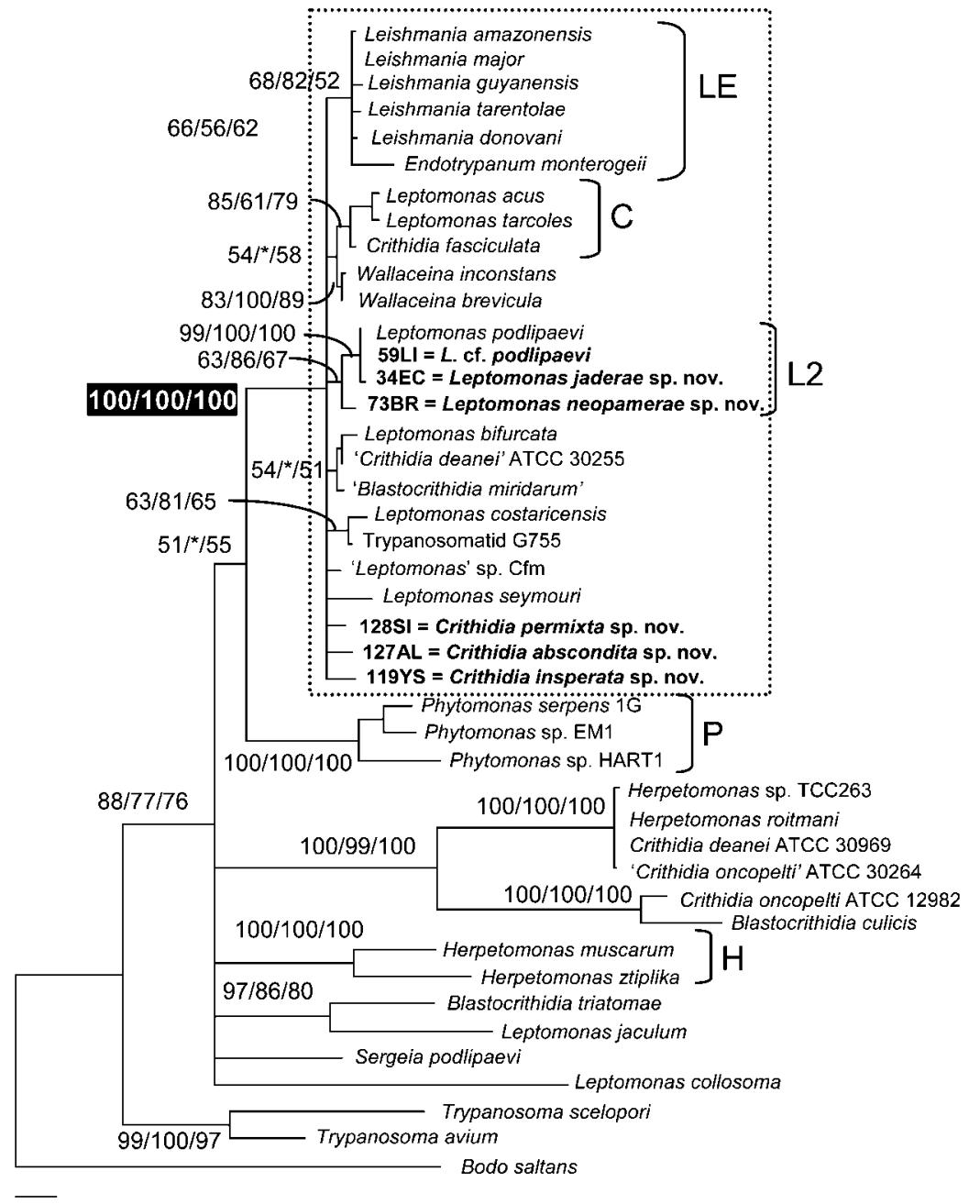

Fig. 5. SSU rRNA gene phylogenetic tree of Trypanosomatidae showing the positions of the novel trypanosomatid species. The bootstrap consensus $\mathrm{ML}$ tree shown ( $L n$-likelihood $=-8078.56036)$ was derived by heuristic search with 100 replicates. Other bootstrap values (\%) were derived and presented as in Fig. 4. Bar, 0.01 substitutions per site. The best ML tree (not shown, Lnlikelihood $=-7976.95487$ ) was derived with a heuristic search and the GTR model with $\mathrm{I}=0.5815$ and $\Gamma=0.6291$. characteristic choanoflagellate body shape observed in most cells.

Specific characters. The morphology is similar to $C$. insperata sp. nov. although the furrows on the cell surface are less pronounced. The novel species is clearly distinguishable by the sequence of an SL RNA gene repeat (EU088274) and the SSU rRNA and gGAPDH gene sequences.

Type host. Intestine of Largus sp. (Heteroptera, Largidae). The xenotype - UCRC ENT 138540.

Type locality. In the vicinity of Puerto Napo $\left(01^{\circ} 02^{\prime} 55^{\prime \prime} \mathrm{S}\right.$ $\left.77^{\circ} 36^{\prime} 07^{\prime \prime} \mathrm{W}\right)$, Province Napo, Ecuador.

Type material. The hapantotype - the type culture of 127AL (ATCC PRA-262), also stored in the collection of the Institute of Parasitology (Budweis, Czech Republic).

Etymology. The Latin word 'absconditus' (hidden) reflects a concealed presence of the novel species in the original host that remained undetected by the original cultureindependent analysis.

\section{Crithidia permixta sp. nov. Maslov and Lukeš}

Genus assignment. Based on the presence of choanomastigotes in culture, the organism has been assigned to the genus Crithidia Léger, 1902.

Specific characters. The morphology in culture in addition to choanomastigotes, includes short promastigotes, amastigotes and sphaeromastigotes. The cells are medium-sized $(6.2-10.5 \mu \mathrm{m})$ with a slightly longer flagellum. The flagellar pocket frequently opens to the side of the main body axis. The cell surface is unsculptured. The species is primarily defined and distinguished from other species by the sequences of the SL RNA gene repeats (GenBank accession numbers EU088275, EU088276), as well as the gGAPDH and SSU rRNA gene sequences. 
Type host. Intestine of an unidentified species of the tribe Mirini (Heteroptera, Miridae). The xenotype - UCRC ENT 138638.

Type locality. In the San Isidro forest reserve, in the vicinity of Cosanga $\left(00^{\circ} 35^{\prime} 27^{\prime \prime} \mathrm{S} 77^{\circ} 52^{\prime} 51^{\prime \prime} \mathrm{W}\right)$, Province Napo, Ecuador.

Type material. The hapantotype - the type culture of 128SI (ATCC PRA-261), also stored in the collection of the Institute of Parasitology (Budweis, Czech Republic).

Etymology. The species name (Latin 'permixtio' - a mixture, a confusion) indicates that the novel species was a component of a mixed infection.

\section{DISCUSSION}

In spite of the unquestionable importance of PCR-based genotyping and metagenomics approaches, some aspects of microbiological research, including detailed ultrastructure, as well as biochemical and molecular studies, still depend on the availability of micro-organisms in culture. This is fully applicable to Trypanosomatidae, and the need to establish and investigate laboratory cultures from a broad range of species, and not only the pathogenic species, was recognized long ago (Wallace et al., 1983).

A major anticipated caveat on this path is a cultivationimposed selection for faster growing members of mixed infections that occurs in parallel with a counter-selection of more fastidious components (Podlipaev \& Frolov, 1987; Podlipaev, 2000, 2003). Cultures thus obtained would misrepresent original mixed infections. Infection of a single insect host with several morphologically diverse parasites, including epi-, choano-, pro-, opistho- and amastigotes, have been reported (Carvalho \& Deane, 1974). The derived cultural forms, however, invariably lacked epimastigotes, indicating that these blastocrithidia-like organisms, although abundant in the host, were not cultivable. Indeed, a number of authors have commented on the difficulty of growing Blastocrithidia spp. in culture (Wallace, 1966; Carvalho \& Deane, 1974; Peng \& Wallace, 1981), with the exception of Blastocrithidia culicis, which bears endosymbionts that alleviates its nutritional requirements, as in other endosymbiont-bearing trypanosomatids (Chang, 1975; De Menezes \& Roitman, 1991; Faria e Silva et al., 1991; Motta et al., 1997).

Furthermore, several species of insect trypanosomatids, including Blastocrithidia gerricola and Blastocrithidia miridarum, were described by Podlipaev and coworkers based on characteristic epimastigote morphology of the parasites observed in the original hosts (Podlipaev, 1985; Podlipaev \& Frolov, 1987). The isolated culture of 'Blastocrithidia gerricola' did not match the original description and thus was suspected to represent a Wallaceina sp. that was present as a minor component in the infected host (Bulat et al., 1999; Merzlyak et al., 2001). Similarly, the characteristics of cells in cultures of 'Blastocrithidia miridarum', 'Leptomonas peterhoffi', 'Leptomonas' sp. $\mathrm{Cfm}$, and 'Leptomonas' sp. F6 are clearly different from the morphology of cells in the original respective insect hosts (Podlipaev \& Frolov, 1987; Merzlyak et al., 2001) (A. Kostygov, personal communication). Instead, the culture cells of 'Leptomonas peterhoffi' and 'Leptomonas' sp. F6 were morphologically and phylogenetically very close to Wallaceina, whereas cells in the cultures of 'Blastocrithidia miridarum' and 'Leptomonas' sp. Cfm represented some unique members of the 'SE' clade (Merzlyak et al., 2001; Yurchenko et al., 2006a) (Figs 4 and 5). Thus, whereas the Blastocrithidia spp. are frequently found as predominant components of mixed infections, these organisms appear to be replaced in culture with other, less fastidious parasites. However, without an objective comparison of parasites in the original host and the respective culture, this scenario would remain hypothetical.

The development of a culture-independent approach to the analysis of trypanosomatids directly from nature (Westenberger et al., 2004; Maslov et al., 2007) has allowed us to obtain the missing evidence for cultivation-imposed selection. Mixed trypanosomatid infections in single host were documented in several cases when an insect was found to harbour two or three types of parasites (Maslov et al., 2007). As described in the present work, a culture was obtained from the specimen of Largus sp. that had been found to harbour two different Blastocrithidia-like trypanosomatids 127AL-A and 127AL-B. The analysis of the organism recovered in culture showed that it represented a novel trypanosomatid species, Crithidia abscondita sp. nov., strain 127AL, indicating that the original host was actually infected with three different types of parasites. Apparently, the two blastocrithidias detected in the original PCR-based analysis were out-competed in culture by the faster growing Crithidia species that had not been detected initially.

Similarly, in the course of the present study we found that the axenic cultures derived from the infected samples 59LI (=Leptomonas cf. podlipaevi), 119YS (=C. insperata sp. nov.) and 128SI (=C. permixta sp. nov.) were different from the blastocrithidias that had been detected originally in the respective hosts (Maslov et al., 2007). Again, this indicates that the original infections contained two types of parasites with differences in abundance and cultivation properties. The blastocrithidia-like organisms were predominant in the natural infections, and were detected and genotyped by using a PCR-based assay, but were not prone to cultivation, at least under the conditions employed. The original population of parasites in the hosts must also have contained low abundant crithidias and leptomonads, and these parasites were eventually recovered in the axenic cultures. In all cases but one (59LI=Leptomonas cf. podlipaevi) the cultivable organisms described herein represented novel species, thereby ruling out the possibility that their presence in culture in lieu of the initially 
encountered parasites was caused by contamination or culture mix-up.

Why the minor components of the natural infections evaded detection during the culture-independent survey (Maslov et al., 2007; Westenberger et al., 2004) needs to be analysed further. This possibly involves template competition between the components with different abundance, as well as by properties of the templates with respect to the nucleotide composition, length and potential secondary structure of single-stranded DNA during the reaction. In any case, the fact that the novel species were not detected earlier illustrates a potential bias of using an exclusively PCR-based approach.

The fact that the endosymbiont-bearing strains of $C$. deanei and $C$. oncopelti are quite different from their endosymbiont-free derivatives deserves an explanation. The case of C. deanei is apparently a strain mix-up, as was suggested previously (Clark, 1997): we found that the supposedly endosymbiont-bearing strain of ' $C$. deanei' (ATCC 30255), obtained from the American Type Culture Collection, was actually devoid of endosymbionts (data not shown). The analysis of SL RNA gene repeats from this strain (Fig. 3) showed that this organism was very close to Crithidia luciliae thermophila. At the same time, the original strain of C. deanei does contain endosymbionts (Freymuller \& Camargo, 1981; Gadelha et al., 2005), and we also found that the SL RNA gene repeats from that strain are identical to those of the $C$. deanei apoendosymbiontic strain ATCC 30969 (data not shown), as expected. This also indicates that strain ATCC 30255 (the one that is closely related to $C$. luciliae thermophila) does not represent the original endosymbiont-bearing strain of $C$. deanei.

In the case of $C$. oncopelti, our analyses showed that the endosymbiont-free derivative ' $C$. oncopelti' ATCC 30264 was a different organism compared to the original endosymbiont-bearing $C$. oncopelti ATCC 12982. In this case, however, the authenticity of the apoendosymbiontic derivative ATCC 30264 was in doubt. Based on the sequences of gGAPDH, SSU rRNA genes and SL RNA gene repeats (Figs $3-5$ ), the endosymbiont-bearing strain is well-separated species, whereas the endosymbiont-free ' $C$. oncopelti' ATCC 30264 is actually indistinguishable from the endosymbiontfree C. deanei ATCC 30969. Moreover, the sequences from both of these apoendosymbiontic organisms are practically identical to the sequences from two species of Herpetomonas: H. roitmani TCC080 and Herpetomonas sp. TCC263. While it is possible that C. deanei and both strains of Herpetomonas are in fact close relatives, as also suggested independently by the same size of their unusually large size $(\sim 4.2 \mathrm{~kb})$ kinetoplast DNA minicircles (Hollar et al., 1998; Brandão et al., 2000), this group does not include endosymbiontbearing $C$. oncopelti by any molecular criteria. Hence the apoendosymbiontic 'C. oncopelti' ATCC 30264 is most likely to be not authentic.

In any case, the discrepancies described above have highlighted once more the importance of an authenticity check using suitable molecular markers, which must be carried out on a periodic basis. The sequences of SL RNA gene repeat units, and sometimes just their size alone, are well suited for this purpose.

Most of the cultivable isolates, including the novel Crithidia and Leptomonas species described in the present work, belong to the 'SE' clade, which now emerges as one of the major subdivisions within the family Trypanosomatidae. This clade includes both monoxenous (the majority of lineages) and dixenous (Leishmania) organisms that demonstrate a rather broad range of morphotypes, including promastigotes (Leptomonas and the other genera), choanomastigotes (Crithidia), endomastigotes (Wallaceina) and amastigotes (Leishmania and the other genera). Quite often little correlation between morphology and phylogeny is observed; this is especially evident for the Crithidia and Leptomonas species that mingle in the tree. The fact that closely related organisms differ morphologically and, conversely, that distantly related organisms show similar morphotypes indicate that the evolution of body shape, at least within the 'SE' clade, included convergence and reversals.

Such frequent and parallel changes were possible probably because all the morphotypes listed above can be viewed as derivatives of the basic promastigote body shape undergoing shortening of the flagellum and the body or deepening of the flagellar pocket. Considering the cases of 'Blastocrithidia gerricola' and 'Blastocrithidia miridarum' as misnomers, and taking into account the dubious nature of the genus Endotrypanum (Cupolillo et al., 2000), no species with an undulating membrane or a side opening of the flagellar pocket has been found in this clade. Yet, the promastigote morphology and its derivatives in general do not represent a synapomorphy that can be used to define this group because it is shared by several other major phylogenetic lineages of the Trypanosomatidae (e.g. ' $\mathrm{P}$ ' and ' $\mathrm{H}$ ' clades). Thus, at this time the 'SE' clade remains to be characterized only phylogenetically, although it does so with a very high level of bootstrap support.

The opisthomastigote morphotype used to define the genus Herpetomonas (Hoare \& Wallace, 1966) is not shared by all members of the respective clade (clade ' $\mathrm{H}$ '), as illustrated by a recently described member of this clade, Herpetomonas ztiplika, which apparently lacks this morphotype (Podlipaev et al., 2004). No opisthomastigotes were found in the novel isolate 37EC and its close relative Leptomonas lactosovorans which, despite its present genus assignment (Manaia et al., 1981), definitely belongs to this phylogenetically well-supported group.

With respect to the monoxenous parasites, the trees shown in Figs 3-5 are among the most comprehensive trypanosomatid phylogenies published so far. However, being restricted to the isolates available in culture, the phylogenetic analyses have not yet reached the deep strata of uncultivable or uncultivated species, which may represent the majority of the family. The culture-independent SL 
rRNA gene-based survey (Maslov et al., 2007) has provided a glimpse into this poorly known and potentially speciesrich diversity which still awaits its full discovery.

\section{ACKNOWLEDGEMENTS}

We thank Christine Kim, Jana Fišáková and Martina Tesařová for technical assistance and A. Kostygov for discussions. This work was supported by a UCR Academic Senate grant to D. A. M. and also in part by grants 2B06129 and LC07032 from the Ministry of Education of the Czech Republic to J. L.

\section{REFERENCES}

Bosseno, M. F., Yacsik, N., Vargas, F. \& Breniere, S. F. (2000). Selection of Trypanosoma cruzi clonal genotypes (clonet 20 and 39) isolated from Bolivian triatomines following subculture in liquid medium. Mem Inst Oswaldo Cruz 95, 601-607.

Brandão, A. A., Miranda, A., Degrave, W. M. \& Sousa, M. A. (2000). The heterogeneity of choanomastigote-shaped trypanosomatids as analyzed by their kDNA minicircle size: taxonomic implications. Parasitol Res 86, 809-812.

Brooker, B. E. (1971). The fine structure of Crithidia fasciculata with special reference to the organelles involved in the ingestion and digestion of proteins. $Z$ Zellforsch 116, 532-563.

Brun, R. \& Schönenberger, M. (1979). Cultivation and in vitro cloning of procyclic culture forms of Trypanosoma brucei in a semidefined medium. Acta Trop 36, 289-292.

Bulat, S. A., Mokrousov, I. V. \& Podlipaev, S. A. (1999). Classification of trypanosomatids from insects and plants by the UP-PCR (universally-primed PCR) technique and cross dot blot hybridization of PCR products. Eur J Protistol 35, 319-326.

Camargo, E. P. (1999). Phytomonas and other trypanosomatid parasites of plants and fruit. Adv Parasitol 42, 29-112.

Carvalho, A. L. M. \& Deane, M. P. (1974). Trypanosomatidae isolated from Zelus leucogrammus (Perty, 1834) (Hemiptera, Reduviidae), with a discussion on flagellates of insectivorous bugs. J Protozool 21, $5-8$.

Chang, K.-P. (1975). Reduced growth of Blastocrithidia culicis and Crithidia oncopelti freed of intracellular symbionts by chloramphenicol. J Protozool 22, 271-276.

Clark, C. G. (1997). Riboprinting: a tool for the study of genetic diversity in microorganisms. J Eukaryot Microbiol 44, 277-283.

Cupolillo, E., Medina-Acosta, E., Noyes, H., Momen, H. \& Grimaldi, G., Jr (2000). A revised classification for Leishmania and Endotrypanum. Parasitol Today 16, 142-144.

De Menezes, M. C. N. D. \& Roitman, I. (1991). Nutritional requirements of Blastocrithidia culicis, a trypanosomatid with an endosymbiont. J Eukaryot Microbiol 38, 122-123.

Dey, T., Afrin, F., Anam, K. \& Ali, N. (2002). Infectivity and virulence of Leishmania donovani promastigotes: a role for media, source, and strain of parasite. J Eukaryot Microbiol 49, 270-274.

Doležel, D., Jirků, M., Maslov, D. A. \& Lukeš, J. (2000). Phylogeny of the bodonid flagellates (Kinetoplastida) based on small-subunit rRNA gene sequences. Int J Syst Evol Microbiol 50, 1943-1951.

Dukes, P., McNamara, J. J. \& Godfrey, D. G. (1991). Elusive trypanosomes. Ann Trop Med Parasitol 85, 21-32.

Faria e Silva, P. M., Solé-Cava, A. M., Soares, M. J., Motta, M. C. M., Fiorini, J. E. \& de Souza, W. (1991). Herpetomonas roitmani (Fiorini et al., 1989) n. comb.: a trypanosomatid with a bacterium-like endosymbiont in the cytoplasm. J Protozool 38, 489-494.

Freymuller, E. \& Camargo, E. (1981). Ultrastructural differences between species of trypanosomatids with and without endosymbionts. J Protozool 28, 175-182.

Gadelha, C., Wickstead, B., de Souza, W., Gull, K. \& Cunha-e-Silva, N. (2005). Cryptic paraflagellar rod in endosymbiont-containing kinetoplastid protozoa. Eukaryot Cell 4, 516-525.

Hoare, C. A. \& Wallace, F. G. (1966). Developmental stages of trypanosomatid flagellates: a new terminology. Nature 212, 13851386.

Hollar, L., Lukeš, J. \& Maslov, D. A. (1998). Monophyly of endosymbiont containing trypanosomatids: Phylogeny versus taxonomy. J Eukaryot Microbiol 45, 293-297.

Jamonneau, V., Garcia, A., Ravel, S., Cuny, G., Oury, B., Solano, P., N'guessan, P., N'dri, L., Sanon, R. \& other authors (2002). Genetic characterization of Trypanosoma brucei gambiense and clinical evolution of human African trypanosomiasis in Côte d'Ivoire. Trop Med Int Health 7, 610-621.

Jamonneau, V., Ravel, S., Koffi, M., Kaba, D., Zeze, D. G., Ndri, L., Sane, B., Coulibaly, B., Cuny, G. \& Solano, P. (2004). Mixed infections of trypanosomes in tsetse and pigs and their epidemiological significance in a sleeping sickness focus of Côte d'Ivoire. Parasitology 129, 693-702.

Kostygov, A. I. \& Frolov, A. O. (2007). Leptomonas jaculum (Leger, 1902) Woodcock 1914: a leptomonas or a blastocrithidia? Parazitologiia 41, 126-136.

Lukeš, J. \& Votýpka, J. (2000). Trypanosoma avium: novel features of the kinetoplast structure. Exp Parasitol 96, 178-181.

Lukeš, J., Jirků, M., Doležel, D., Kral’ová, I., Hollar, L. \& Maslov, D. A. (1997). Analysis of ribosomal RNA genes suggests that trypanosomes are monophyletic. J Mol Evol 44, 521-527.

Manaia, A., De Souza, M., Lustoza, E. \& Roitman, I. (1981). Leptomonas lactosovorans $\mathrm{n}$. sp., a lactose-utilizing trypanosomatid: description and nutritional requirements. J Eukaryot Microbiol 28, 124-126.

Masiga, D. K., McNamara, J. J., Laveissiere, C., Truc, P. \& Gibson, W. C. (1996). A high prevalence of mixed trypanosome infections in tsetse flies in Sinfra, Côte d'Ivoire, detected by DNA amplification. Parasitology 112, 75-80.

Maslov, D. A., Westenberger, S. J., Xu, X., Campbell, D. A. \& Sturm, N. R. (2007). Discovery and barcoding by analysis of spliced leader RNA gene sequences of new isolates of Trypanosomatidae from Heteroptera in Costa Rica and Ecuador. J Eukaryot Microbiol 54, 57-65.

Merzlyak, E., Yurchenko, V., Kolesnikov, A. A., Alexandrov, K., Podlipaev, S. A. \& Maslov, D. A. (2001). Diversity and phylogeny of insect trypanosomatids based on small subunit rRNA genes: polyphyly of Leptomonas and Blastocrithidia. J Eukaryot Microbiol 48, 161-169.

Motta, M. C. M., Soares, M. J., Attias, M., Morgado, J., Lemos, A. D. P., Saad-Nehme, J., Meyer-Fernandes, J. R. \& de Souza, W. (1997). Ultrastructural and biochemical analysis of the relationship of Crithidia deanei with its endosymbiont. Eur J Cell Biol 72, 370-377.

Njiokou, F., Simo, G., Nkinin, S. W., Laveissiere, C. \& Herder, S. (2004). Infection rate of Trypanosoma brucei s.l., T. vivax, T. congolense "forest type", and T. simiae in small wild vertebrates in south Cameroon. Acta Trop 92, 139-146.

Peng, P. L. M. \& Wallace, F. G. (1981). The cultivation of Blastocrithidia triatomae Cerisola et al., 1971. J Protozool 28, 116-118.

Podlipaev, S. A. (1985). New species of lower trypanosomatids from insects (Hemiptera: Heteroptera) belonging to the families Gerridae 
and Nabidae: their life cycle stages in nature and in culture. Proc Zool Inst USSR Acad Sci 129, 35-47.

Podlipaev, S. A. (1990). Catalogue of world fauna of Trypanosomatidae (Protozoa). Proc Zool Inst Leningrad 144, 1-178.

Podlipaev, S. A. (2000). Insect trypanosomatids: the need to know more. Mem Inst Oswaldo Cruz 95, 517-522.

Podlipaev, S. A. (2001). The more insect trypanosomatids under study - the more diverse trypanosomatidae appears. Int J Parasitol 31, 648-652.

Podlipaev, S. A. (2003). Host specificity of homoxenous trypanosomatids. Parazitologiia 37, 3-17.

Podlipaev, S. A. \& Frolov, A. O. (1987). Description and laboratory cultivation of Blastocrithidia miridarum sp. n. (Mastigophora, Trypanosomatidae). Parasitologia 21, 545-552.

Podlipaev, S., Votýpka, J., Jirků, M., Svobodová, M. \& Lukeš, J. (2004). Herpetomonas ztiplika n. sp. (Kinetoplastida: Trypanosomatidae): a parasite of the blood-sucking biting midge Culicoides kibunensis Tokunaga, 1937 (Diptera: Ceratopogonidae). J Parasitol 90 , 342-347.

Posada, D. \& Crandall, K. A. (1998). MODELTEST: testing the model of DNA substitution. Bioinformatics 14, 817-818.

Reduth, D., Schaub, G. A. \& Pudney, M. (1989). Cultivation of Blastocrithidia triatomae (Trypanosomatidae) on a cell line of its host Triatoma infestans (Reduviidae). Parasitology 98, 387-393.

Reifenberg, J. M., Solano, P., Duvallet, G., Cuisance, D., Simpore, J. \& Cuny, G. (1997). Molecular characterization of trypanosome isolates from naturally infected domestic animals in Burkina Faso. Vet Parasitol 71, 251-262.

Simpson, L., Thiemann, O. H., Savill, N. J., Alfonzo, J. D. \& Maslov, D. A. (2000). Evolution of RNA editing in trypanosome mitochondria. Proc Natl Acad Sci U S A 97, 6986-6993.

Simpson, A. G., Stevens, J. R. \& Lukeš, J. (2006). The evolution and diversity of kinetoplastid flagellates. Trends Parasitol 22, 168-174.

Stevens, J. R., Mathieu-Daudé, F., McNamara, J. J., Mizen, V. H. \& Nzila, A. (1994). Mixed populations of Trypanosoma brucei in wild Glossina palpalis palpalis. Trop Med Parasitol 45, 313-318.
Swofford, D. L. (1998). PAUP* 4.0: Phylogenetic Analysis Using Parsimony (and other methods), beta version. Sunderland, MA: Sinauer Associates.

Thompson, J. D., Gibson, T. J., Plewniak, F., Jeanmougin, F. \& Higgins, D. G. (1997). The CLUSTAL_X windows interface: flexible strategies for multiple sequence alignment aided by quality analysis tools. Nucleic Acids Res 25, 4876-4882.

Vickerman, K. (1976). The diversity of the kinetoplastid flagellates. In Biology of the Kinetoplastida, pp. 1-34. Edited by W. H. R. Lumsden \& D. A. Evans. London: Academic Press.

Wallace, F. G. (1966). The trypanosomatid parasites of insects and arachnids. Exp Parasitol 18, 124-193.

Wallace, F. G., Camargo, E. P., McGhee, R. B. \& Roitman, I. (1983). Guidelines for the description of new species of lower trypanosomatids. J Protozool 30, 308-313.

Westenberger, S. J., Sturm, N. R., Yanega, D., Podlipaev, S. A., Zeledón, R., Campbell, D. A. \& Maslov, D. A. (2004). Trypanosomatid biodiversity in Costa Rica: genotyping of parasites from Heteroptera using the spliced leader RNA gene. Parasitology 129, 537547.

Yurchenko, V. Y. \& Kolesnikov, A. A. (2001). Minicircular kinetoplast DNA of Trypanosomatidae. Mol Biol (Mosk) 35, 3-13.

Yurchenko, V., Lukeš, J., Xu, X. \& Maslov, D. A. (2006a). An integrated morphological and molecular approach to a new species description in the Trypanosomatidae: the case of Leptomonas podlipaevi n. sp., a parasite of Boisea rubrolineata (Hemiptera: Rhopalidae). J Eukaryot Microbiol 53, 103-111.

Yurchenko, V. Y., Lukeš, J., Jirků, M., Zeledón, R. \& Maslov, D. A. (2006b). Leptomonas costaricensis sp. n. (Kinetoplastea: Trypanosomatidae), a member of the novel phylogenetic group of insect trypanosomatids closely related to the genus Leishmania. Parasitology 133, 537-546.

Yurchenko, V. Y., Lukeš, J., Tesařová, M., Jirků, M. \& Maslov, D. A. (2008). Morphological discordance of the new trypanosomatid species phylogenetically associated with the genus Crithidia. Protist 159, 99-114. 